\title{
Review \\ Effectiveness of Augmented Reality in Stroke Rehabilitation: A Meta-Analysis
}

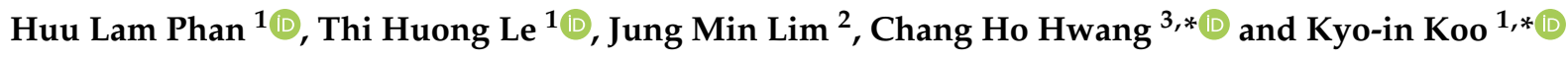 \\ 1 Department of Electrical, Electronic and Computer Engineering, University of Ulsan, Ulsan 44610, Korea; \\ phlam.ulsan@gmail.com (H.L.P.); lehuong94alhp@gmail.com (T.H.L.) \\ 2 Office of Si-Heung Campus, Future Innovation Institute, Seoul National University, Seoul 15011, Korea; \\ apomega@snu.ac.kr \\ 3 Department of Physical \& Rehabilitation Medicine, Chungnam National University Sejong Hospital, \\ Chungnam National University College of Medicine, Sejong 30099, Korea \\ * Correspondence: chhwang1220@cnu.ac.kr (C.H.H.); kikoo@ulsan.ac.kr (K.-i.K.); \\ Tel.: +82-44-995-4715 (C.H.H.); +82-52-259-1408 (К.-i.K.)
}

Citation: Phan, H.L.; Le, T.H.; Lim, J.M.; Hwang, C.H.; Koo, K.-i. Effectiveness of Augmented Reality in Stroke Rehabilitation: A

Meta-Analysis. Appl. Sci. 2022, 12, 1848. https://doi.org/10.3390/ app12041848

Academic Editors: Enrico Vezzetti and Pietro Piazzolla

Received: 7 December 2021

Accepted: 7 February 2022

Published: 11 February 2022

Publisher's Note: MDPI stays neutral with regard to jurisdictional claims in published maps and institutional affiliations.

Copyright: (C) 2022 by the authors. Licensee MDPI, Basel, Switzerland. This article is an open access article distributed under the terms and conditions of the Creative Commons Attribution (CC BY) license (https:// creativecommons.org/licenses/by/ $4.0 /)$.

\begin{abstract}
Augmented reality (AR)-based rehabilitation shows potential to improve upper and lower limb function after stroke. This study aims to review the effect of AR technology in the recovery of the upper and lower limb function in stroke patients. Published randomized controlled trials and observational investigations with adult stroke patients were retrieved from five electronic databases to analyze the effect of the AR systems in improving motor function and balance and gait function for stroke patients. The treatment effect was estimated by standardized mean difference (SMD) and 95\% confidence interval (CI) using a random effect model for motor function outcomes at the body structure and function, body activity and participation level of the International Classification of Functioning, and balance and gait outcomes. In total, 13 investigations ( 9 for the upper limb and 4 for the lower limb) were identified. AR demonstrated a significant influence on the upper limb function $(\mathrm{SMD}=0.657 ; 95 \% \mathrm{CI}, 0.287$ to $1.026 ; p=0.000)$ and the lower limb function (SMD $=0.52 ; 95 \% \mathrm{CI}$, 0.039 to $1.001 ; p=0.034$ ). The present analysis suggests that AR applications could offer options for increasing treatment intensity and promoting motor recovery after a stroke. This approach can be used with the conventional rehabilitation methods as a new intervention for recovering upper and lower limb function.
\end{abstract}

Keywords: augmented reality; stroke; upper extremity; lower limb; rehabilitation

\section{Introduction}

Stroke is one of the most common causes of disability and poor quality of life [1,2]. In addition, it affects health and social care systems by poor performance at work, increased dependency, and demands on healthcare [3]. Because the upper limbs (ULs) and lower limbs (LLs) are involved in the majority of daily living activities, it is necessary to improve ULs and LLs' functional utilization after stroke. To enhance their quality of life, rehabilitation plays a key role in the recovery of function for the patients [2,4]. In particular, the term "Rehabilitation" for stroke patients is defined as targeted neuromodulation of abnormal inter- or within-hemispheric connectivity to promote neural plasticity [5-8]. The rehabilitation systems should have repetitive, challenging, motivating, and intensive exercises to enhance the efficacy of neural plasticity for the patients. Traditional rehabilitation methods are often performed with external instruments such as treadmill ambulation using harness suspension and manual assistance by physical therapists, and arm skating onboard which supports the movement of the hand for upper limb rehabilitation $[9,10]$. Majority of the traditional systems presented to improve activities of daily living performance and increase patients' independence [11,12]. However, these methods are becoming more and more expensive because they require one-to-one therapist-patient activity. The 
simple and repetitive exercises induce boredom in the patients, which reduces their motivation [13]. Furthermore, treatment data are not collected because simple exercising devices are designed with no sensors.

Due to these limitations, the requirement for more interactive and automatic rehabilitation therapeutic tools has accumulated. Thanks to recent rapid progress in electrical and mechanical engineering, new concepts in the rehabilitation therapeutic tool, such as robotic system, virtual reality (VR) system, and AR system, have been proposed and tested. These new conceptual tools bring about several advantages: (1) highly motivated and repetitive exercises without therapist's assistance; and (2) stimulation of brain plasticity for fast recovery of motor functions. AR is a technology that combines real and virtual objects to provide an interactive experience in real time in a common environment [14]. During the intervention, patients are guided and corrected by reliable and accurate feedback of the virtual objects which AR accommodates to enhance motor learning and motivation [15,16]. The virtual interactive objects created by AR in the real world induce more embodiment toward users than those created by VR in the virtual world [17]. Moreover, AR creates a safe environment to allow users to interact with real objects in real-world circumstances. It is easily modified to adapt to the individual's impairment or personal preferences. As AR technology becomes more accessible and affordable, AR interventions could be used widely in clinical rehabilitation settings. Hence, determining the efficacy of AR treatments in stroke recovery is crucial to guide future utilization for clinicians.

Many reports reviewed AR technology in the rehabilitation field [18-21]. These articles only reviewed information on AR technology and described the obtained results in the clinical rehabilitation of each study. However, no meta-analysis of AR applications in motor recovery has been conducted. Based on the main findings of a single study, it is not enough evidence to conclude whether AR has effectiveness in this field for the clinicians, because their findings are not statistically significant. This paper conducted a meta-analysis to evaluate the effectiveness of the AR for the upper and lower limb functional recovery after stroke and to provide some potential implications for clinicians to consider using AR in rehabilitation in the future.

\section{Methods}

\subsection{Objective}

This review aims to determine the effectiveness of AR on upper limb function, gait and balance based on collected publications. Articles were selected and analyzed following the Preferred Reporting Items for Systematic Review and Meta-Analyses (PRISMA) guidelines [22]; it should be noted that the protocol was not registered.

\subsection{Search Strategy}

Our systematic search was performed in October 2021 for published articles available on PubMed (Medline), Web of Science (WOS), Science Direct, Embase, and SAGE Publication. The searching keywords are (Augmented Reality OR AR) AND (stroke OR Hemiplegia) AND (rehabilitation) AND (Upper Limb OR Upper Extremity OR Lower Limb OR Lower Extremity OR Gait and Balance) (Table 1).

Table 1. The searching methods and results in the databases.

\begin{tabular}{ccc}
\hline Databases & Search Syntax & No. of Articles \\
\hline \multirow{3}{*}{ Web of Science } & (Augmented Reality OR AR) AND (stroke OR & \\
& Hemiplegia) AND (rehabilitation) AND (Upper & 41 \\
& Limb OR Upper Extremity OR Lower Limb OR & \\
& Lower Extremity OR Gait and Balance) & \\
Science Direct & (Augmented Reality OR AR) AND (stroke OR & 339 \\
& Hemiplegia) AND (rehabilitation) AND (Upper & \\
& Limb OR Upper Extremity OR Lower Limb OR & \\
& Lower Extremity OR Gait and Balance) & \\
\hline
\end{tabular}


Table 1. Cont.

\begin{tabular}{ccc}
\hline Databases & Search Syntax & No. of Articles \\
\hline \multirow{2}{*}{ PubMed } & (Augmented Reality OR AR) AND (stroke OR & \\
& Hemiplegia) AND (rehabilitation) AND (Upper & 53 \\
& Limb OR Upper Extremity OR Lower Limb OR & \\
& Lower Extremity OR Gait and Balance) & \\
\hline & (Augmented Reality OR AR) AND (stroke OR & \\
Embase & Hemiplegia) AND (rehabilitation) AND (Upper & \\
& Limb OR Upper Extremity OR Lower Limb OR & \\
& Lower Extremity OR Gait and Balance) & \\
& (Augmented Reality OR AR) AND (stroke OR & \\
& Hemiplegia) AND (rehabilitation) AND (Upper & \\
LAGE Publication & Limb Upper Extremity OR Lower Limb OR & \\
& Lower Extremity OR Gait and Balance) & \\
\hline
\end{tabular}

\subsection{Inclusion Criteria}

The inclusion criteria were formed as follows: (1) Randomized controlled trials (RCTs) and observational studies. These studies reported the intervention based on the AR-setting on the patients. They provided enough data to conduct a meta-analysis; (2) The aim of this meta-analysis only focuses on stroke patients. Therefore, participants had to have had an acute, subacute, or chronic stroke; (3) to assess the efficacy of the AR-intervention group versus baseline or conventional therapy groups, the outcome measurements were implemented before undertaking the AR intervention in the baseline group or on a control group that did not receive the AR intervention; (4) In the previous report, Ong et al. reviewed AR technology in the rehabilitation field that the collected articles published from 2000 to 2010 [18]. At that time, AR is still in the exploratory stage in the rehabilitation field. Hence, there are a small number of studies about AR technology for stroke rehabilitation. In addition, no clinical data is reported in these studies. In this meta-analysis, the articles were published in the past 12 years (from 2010 to 2021) and were written in English, and were collected to update the AR technology in stroke rehabilitation.

\subsection{Exclusion Criteria}

Studies were excluded in these cases: (1) the studies were review articles, metaanalyses, books, graduation thesis, conference proceedings or editorial articles; (2) the studies did not have the outcome of interest; (3) the studies were case reports or small case series, including less than 3 patients.

\subsection{Study Selection}

By reading their titles, the duplicate papers were removed using Endnote software. Afterwards, abstract and full-text readings were implemented to eliminate the articles that did not satisfy the formed criteria. Two researchers (H.L.P. and T.H.L.) evaluated all papers separately, and any disagreements were solved through discussion until a consensus was reached.

\subsection{Data Extraction}

The following information was collected from each study: (1) author and date of publication, (2) study design, (3) number and age of participants, (4) time since stroke onset, (5) characteristics of the interventions, (6) outcome measures in each group and results.

\subsection{Type of Outcome Measures}

The AR outcomes in the upper limb rehabilitation were categorized using the two levels of functioning classified by the ICF-WHO [23]: (1) body structure/function, which is physiological functions of body systems (e.g., Fugl Meyer Assessment); (2) body activities and participation level, which alludes to the execution of assignments, and participation 
in the life situation (e.g., Wolf Motor Function Test, the Box and Blocks Test, the subscales of quality of movement, and amount of use of the Motor Activity Log) (Figure 1) [24]. In the lower limb rehabilitation, we extracted data of berg balance scale, time up and go test, gait velocity, muscle strength, and $10 \mathrm{~m}$ walk test. From every investigation, we took absolute scores (mean and standard deviation (SD)) of the baseline, control, and AR treatment groups.

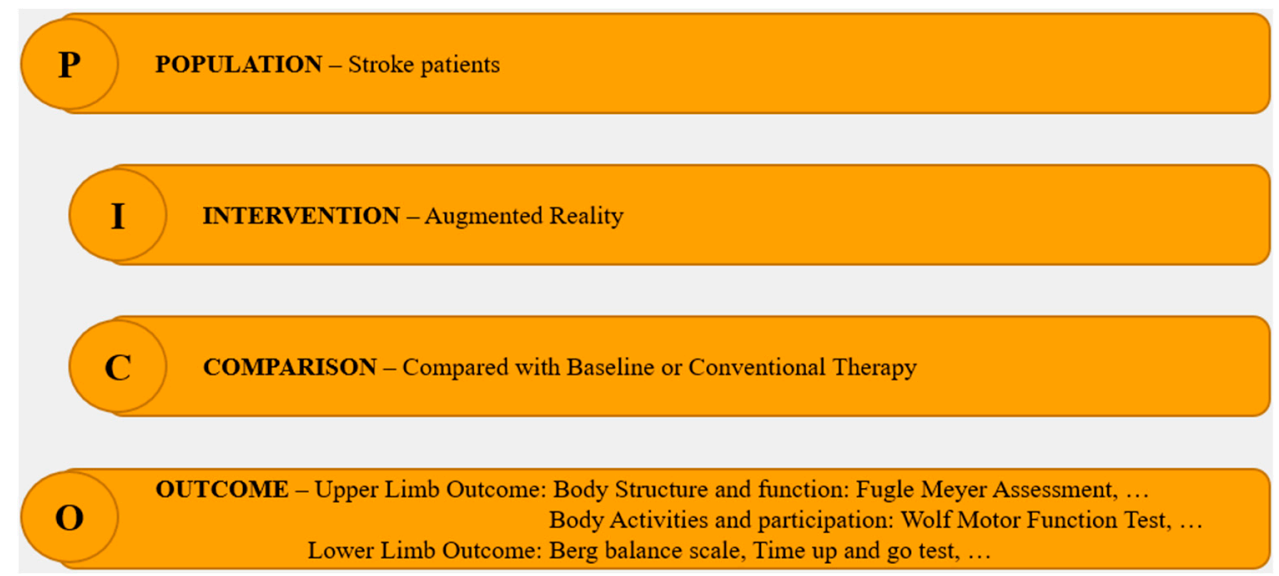

Figure 1. Population, Intervention, Comparison, Outcome (PICO) Question and the main variables included in the systematic review and meta-analysis.

\subsection{Studies Quality Assessment}

Two authors (H.L.P and T.H.L) assessed the bias risk of included investigations using QualSyst [25]. It incorporates 14 questions for quantitative reports and 10 questions for qualitative reports. Here, we used the 14-question set for the searched quantitative articles. The 14-question set deals with the following criteria: (1) research objective description; (2) adequate study design; (3) subject and intervention description; (4) randomization of the subject into groups; (5) outcome measurement; (6) sufficiently detailed outcomes. To implement the evaluation, each question is scored by reviewers relying on their knowledge, these scores being "yes" ( 2 points), "partial" ( 1 point), "no" $(0)$, and "N/A". The final score is given by the average of reviewers' normalized scores. In this manuscript, we chose the investigations with a final score of over $50 \%$, which we considered having high quality.

\subsection{Quantitative Analysis}

The mean, SD, and sample sizes of each outcome measurement in the baseline, control, and AR intervention groups were utilized for comprehensive Meta-analysis (Version 3.0, Biostat Inc., Englewood, NJ, USA). Because the included investigations reported their outcome of different scales, the effect size estimates were computed using SMD and $95 \%$ confidence interval (CI) by a random effect model to depict the magnitude of the enhancement compared with baseline or control group. The interpretation of SMD was as follows: $<0.2$ negligible; $0.2-0.5$ small; $0.5-0.8$ moderate; and $>0.8$ large. For all tests, $p<0.05$ was considered statistically significant. If each group had over one investigation, meta-analysis was implemented. The forest plot was used to describe the effect size of favoring the AR (allocating in a positive value) and baseline or control group (assigning in a negative value). We assessed heterogeneity through inspection of I-square statistic, where I 2 value over $50 \%$ indicates significant heterogeneity. Bias risk across investigations was evaluated using funnel plot and Egger's regression test.

\section{Results and Discussion}

Figure 2 shows the systematic review process. We found 556 records using keywords (Augmented Reality OR AR) AND (stroke OR Hemiplegia) AND (rehabilitation) AND (Upper Limb OR Upper Extremity OR Lower Limb OR Lower Extremity OR Gait and 
Balance) in the five electronic databases as described in Table 1. A total of 22 articles were removed because of duplication, and 534 articles were excluded based on our criteria. Finally, 13 articles were selected through full-text checking. Among the final 13 articles, there were 9 observational investigations for upper limb rehabilitation and 4 investigations for balance and gait.

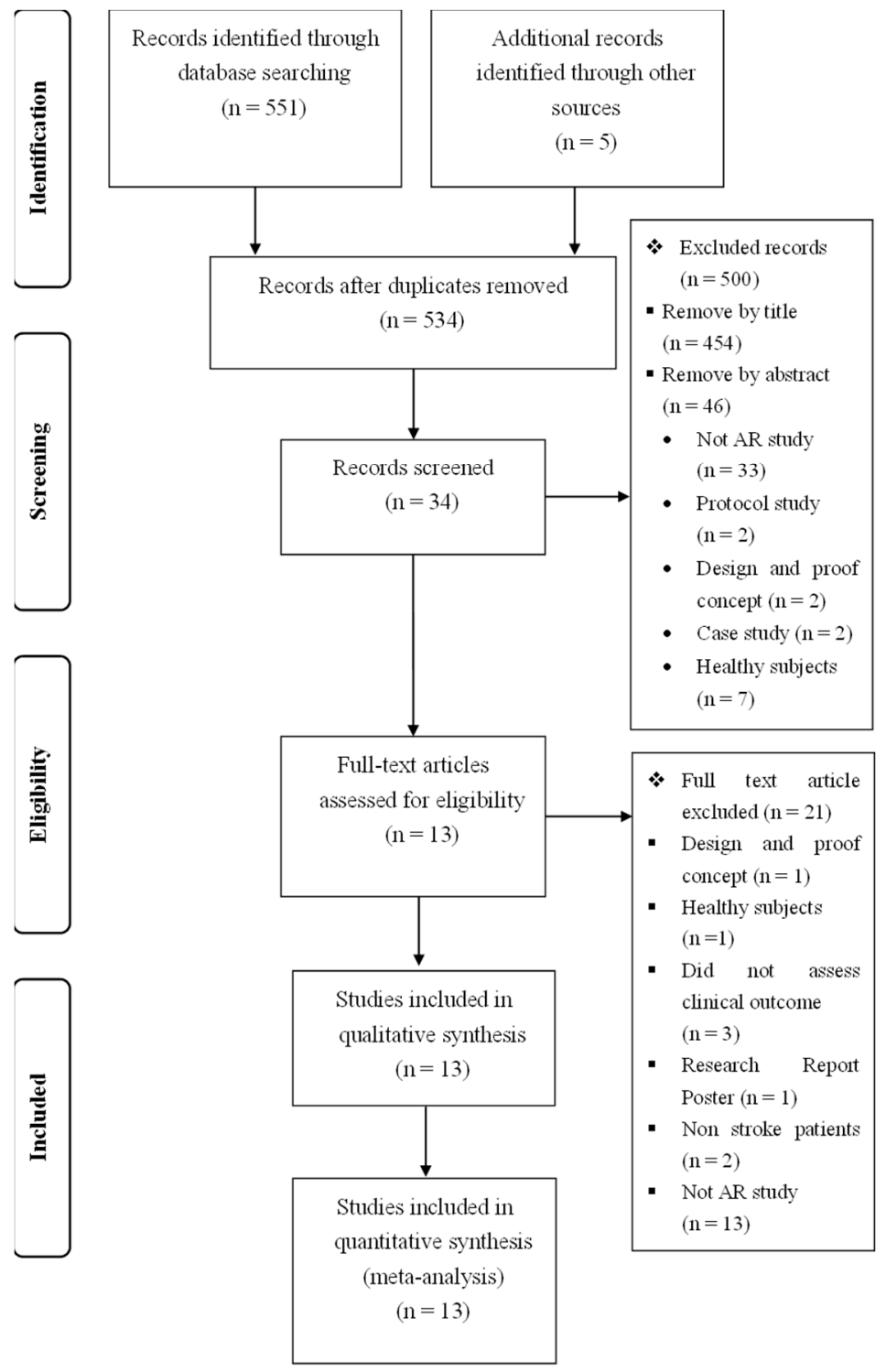

Figure 2. PRISMA study selection flow diagram.

\subsection{AR Technique Overview}

\subsubsection{AR Technique for Upper Limb Rehabilitation}

Nine studies used AR to improve upper limb function. The main type of AR intervention was games, which were specifically described in the literature [26-29]. They provided games to increase motivation, overcoming gravity for patients. Specifically, Marcus King et al. proposed the ARS; that is, a simple AR system for home rehabilitation after stroke [26]. The authors presented two versions: a computer game, and a more advanced version that incorporates a control tool (a computer mouse/arm skate) to increase the physical effort associated with reaching tasks. Additionally, the system includes feedback or factors such as a game score, intellectual stimulation, and social interaction during group play. Hossain et al. developed a framework called post-Stroke Interactive and Entertaining Rehabilitation with Reactive Objects (SIERRA) [27]. In order to increase the patients' per- 
ception of interaction with virtual objects in the environment, they embedded vibrotactile actuators in tangible objects used in the recovery exercise of the SIERRA framework. In the two above AR game systems, they have relied on tracking methods for a prepared environment using the marker-based AR technology that the virtual item is showed if the corresponding marker is detected. Specifically, a pattern using black and white (B/W) fiducial markers is employed for the markers in the above AR systems. This technique is applied in many AR systems because it enables more precise and faster tracking. However, poor lighting environments and marker occlusions are some factors that induce difficulties in marker recognition for the AR systems based on marker tracking. Additionally, screenbased AR technologies are used in these AR rehabilitation systems. The AR system can give a high quality of present and embodiment which helps patients to have more realistic feeling. In order to enhance the sense of immersion, Bank et al. proposed an AR rehabilitation system using the head-mounted display (HMD) device [29]. Besides, this system includes a Leap Motion, an HD Webcam, a Microsoft Kinect v2 sensor connecting with a laptop. The leap motion is utilized for contactless tracking of the hand. Furthermore, the combination of contactless tracking and 3D rendering to overcome the limitations of gloves, makers occlusions in the 3D environment based on the Microsoft Kinect v2 sensor. It helps the patients feel natural when interacting with virtual objects. Three games are designed to assess the speed, hand opening abilities to various size objects, and obstacle avoidance. However, the use of screen-based AR technology and HMD device in these types of AR systems has the limitation of the field of view (FOV) due to the monitor size, the distance between the display and the observer. In addition, discomfort, the weight of the device, and poor brightness of micro-displays are the technical problems of the HMD device. To overcome the narrow FOV limitation of the screen-based AR technique and wearable HMD, Hondori et al. reported an AR rehabilitation system using projector-based spatial displays [28]. This technique provides a large FOV to the patient using front-projection to display images directly on physical surfaces. The AR system is based on the commercial Fruit Ninja game. The game activity was displayed on a tabletop using a projector. When slicing the virtual fruit targets, the patients could directly gaze at the real-hand movement on the tabletop. The system can provide feedback as the game scores to motivate the patients during rehabilitation.

Another type of AR intervention was based on the principle of traditional mirror therapy for upper limb rehabilitation. Conventional mirror therapy uses a real mirror to show the normal movement in the affected limb based on the movement of the unaffected limb in front of a mirror. Although the mirror therapy systems-based AR technology utilizes image processing instead of the real mirror, these systems also include all the functions of the conventional method. For example, Hoerman et al. proposed a system that includes all of the benefits of traditional mirror treatment with the addition of AR technology [30,31]. The component of the AR-mirror therapy system consists of a screen, a webcam, and a PC. The patients do exercises with their unaffected hand, which is recorded using a camera and mirrored on a screen by image processing. This AR system not only provides the same user perception as traditional mirror therapy but also allows a wider range of computer-mediated visual illusions and exercise possibilities than conventional mirror therapy. Another type of AR mirror therapy is proposed by Assis et al. [32]. Their system is called the NeuroR system, which provides motor imagery for patients. Two visual tracking methods apply to this system: (1) glove and physical markers are used to identify the patients' injured arm; (2) the system detects the injured arm using markerless tracking. During the training of the flexion-extension exercises, the system showed the movement of a virtual 3D arm instead of the movement of the paralyzed arm for the patient. Users face the projection screen to observe the movement of the virtual arm while users perform impaired arm movements by electromyographic signals (EMG)-based human-computer interface triggering. The final type of AR system provides the exercise related to activities of daily living such as finger flexion-extension, wrist flexion-extension, and elbow flexionextension based on the tabletop system. Colomer et al. proposed this system by projecting 
a virtual environment onto the tabletop which then reacts according to users' movement using the markless tracking technology (a Kinect depth sensor) [33]. This system provides hands-on multi-touch interaction of the tangible objects for the patients. Furthermore, this system supports the audio-visual feedback of the user performance.

\subsubsection{AR Technique for Lower Limb Function}

Four of the studies reviewed the use of AR for gait, postural, and/or walking training. All studies for lower limb rehabilitation were developed in South Korea. Two randomized controlled trial studies used the AR systems based on postural control training in the AR environment for guiding the stroke patients to perform ideal postural control motions such as lying, sitting, and standing [34,35]. Two remaining studies combined AR system with Functional Electric Stimulation during treadmill gait training [36,37]. Most AR systems utilized a server computer mounted with a camera and a super video HMD connected to an ultra-mobile personal computer. The wireless method applies to exchange the signal between two computers. The patients could watch the modeled movement on one side and the actual movement on another side through the HMD device. Thereby, the patients could compare the patients' movement with the normal movement by watching the modeled movement and listening to a recorded sound.

These AR rehabilitation systems can give a high quality of present and embodiment which helps patients to have more realism feeling by using the HMD device that allows an immersive 3D experience to subjects. Moreover, a combination of visual and audio feedback in these systems motivates and encourages the users during long-term training sessions. Table 2 shows a summary of the AR-based system for upper limb and lower limb rehabilitation. Tables 3 and 4 summarize the characteristics and intervention outcomes of the clinical trial in the selected articles.

Table 2. A summary of the AR-based systems for the upper limb and lower limb rehabilitation.

\begin{tabular}{|c|c|c|c|c|}
\hline Author & AR Rehab System & $\begin{array}{l}\text { Physiotherapy } \\
\text { Application }\end{array}$ & Tracking Method & AR Interface \\
\hline $\begin{array}{l}\text { Marcus King et al. } \\
\quad(2010)[26]\end{array}$ & ARS & Shoulder elbow movements & $\begin{array}{c}\text { Wearable marker-based } \\
\text { AR/Fiducial markers (B/W } \\
\text { pattern), IR Fiducial markers }\end{array}$ & Screen \\
\hline $\begin{array}{c}\text { Assis et al. (2014) } \\
\text { [32] }\end{array}$ & NeuroR & $\begin{array}{c}\text { Shoulder abduction-flexion, } \\
\text { Shoulder horizontal flexion, } \\
\text { Finger extension, Hand } \\
\text { grasping }\end{array}$ & $\begin{array}{l}\text { Wearable's marker-based } \\
\text { AR/Markerless AR/Fiducial } \\
\text { markers (B/W pattern) }\end{array}$ & $\begin{array}{c}\text { Projector/PC } \\
\text { audio speakers }\end{array}$ \\
\hline $\begin{array}{l}\text { Hondori et al. } \\
\text { (2015) [28] }\end{array}$ & $\begin{array}{l}\text { A-based Fruit Ninja } \\
\text { game }\end{array}$ & $\begin{array}{l}\text { Hand movement/Shoulder } \\
\text { movements }\end{array}$ & $\begin{array}{c}\text { Non-wearable marker-based } \\
\text { AR/Colored Fiducial } \\
\text { markers }\end{array}$ & $\begin{array}{c}\text { Projector/PC } \\
\text { audio speakers }\end{array}$ \\
\hline $\begin{array}{l}\text { Hossain et al. (2015) } \\
\text { [27] }\end{array}$ & AR-REHAB & $\begin{array}{l}\text { Hand movement/Wrist } \\
\text { movement }\end{array}$ & Fiducial markers & Screen \\
\hline $\begin{array}{l}\text { Hoermann et al. } \\
\text { (2017) [30] }\end{array}$ & ART & $\begin{array}{l}\text { Fingers extension/Wrist } \\
\text { flexion/extension }\end{array}$ & Markerless AR & Screen/ \\
\hline $\begin{array}{l}\text { Colomer et al. } \\
\text { (2016) [33] }\end{array}$ & AR System & $\begin{array}{c}\text { Wrist } \\
\text { flexion-extension/Elbow } \\
\text { flexion-extension/Finger } \\
\text { flexion-extension/Grasping } \\
\text { objects/Shoulder rotation }\end{array}$ & $\begin{array}{c}\text { Markerless AR (Microsoft, } \\
\text { Kinect) }\end{array}$ & $\begin{array}{l}\text { Projector/PC } \\
\text { audio speakers }\end{array}$ \\
\hline $\begin{array}{l}\text { Hoermann et al. } \\
\text { (2014) [31] }\end{array}$ & ART & Hand movement & $\begin{array}{c}\text { Markerless } \\
\text { AR/finger-tracking } \\
\text { extension }\end{array}$ & Screen \\
\hline $\begin{array}{c}\text { Bank et al. (2018) } \\
\text { [29] }\end{array}$ & AR games & $\begin{array}{c}\text { Wrist movement/Elbow } \\
\text { movement/Shoulder } \\
\text { movement }\end{array}$ & $\begin{array}{c}\text { Leap motion/Microsoft } \\
\text { Kinect }\end{array}$ & $\begin{array}{l}\text { Head-mounted } \\
\text { display }\end{array}$ \\
\hline
\end{tabular}


Table 2. Cont.

\begin{tabular}{|c|c|c|c|c|}
\hline Author & AR Rehab System & $\begin{array}{l}\text { Physiotherapy } \\
\text { Application }\end{array}$ & Tracking Method & AR Interface \\
\hline $\begin{array}{c}\text { Kaneko et al. (2019) } \\
\text { [38] }\end{array}$ & KINVIS & $\begin{array}{c}\text { Shoulder/elbow/forearm/ } \\
\text { wrist/hand movement }\end{array}$ & Markerless AR & Screen \\
\hline $\begin{array}{l}\text { Park et al. (2014) } \\
\text { [34] }\end{array}$ & ARPC system & Balance and gait function & Markerless AR & $\begin{array}{c}\text { Head-mounted } \\
\text { display/PC audio } \\
\text { speakers }\end{array}$ \\
\hline Lee et al. (2014) [35] & $\begin{array}{l}\text { AR-based postural } \\
\text { control training }\end{array}$ & Balance and gait function & Markerless AR & $\begin{array}{l}\text { Head-mounted } \\
\text { display }\end{array}$ \\
\hline $\begin{array}{c}\text { Kim et al. (2012) } \\
\text { [36] }\end{array}$ & AR-FES & $\begin{array}{l}\text { Muscle strength/balance and } \\
\text { gait function }\end{array}$ & Markerless AR & $\begin{array}{l}\text { Head-mounted } \\
\text { display }\end{array}$ \\
\hline $\begin{array}{c}\text { Jung et al. (2013) } \\
\text { [37] }\end{array}$ & ARR-EMG & Ankle dorsiflexion & Markerless AR & $\begin{array}{l}\text { Head-mounted } \\
\text { display }\end{array}$ \\
\hline
\end{tabular}

Table 3. The characteristics of the clinical trial in the included investigations.

\begin{tabular}{|c|c|c|c|c|c|c|}
\hline Author & Design & $\begin{array}{l}\text { Number of } \\
\text { Patients }\end{array}$ & $\begin{array}{l}\text { Mean Age } \\
\text { (Year) }\end{array}$ & $\begin{array}{l}\text { Time since } \\
\text { Stroke Onset }\end{array}$ & $\begin{array}{l}\text { Rehabilitation } \\
\text { Settings }\end{array}$ & Intervention \\
\hline $\begin{array}{l}\text { Marcus King } \\
\text { et al. (2010) [26] }\end{array}$ & Pre/post & 4 & Over 18 & Chronic & $\begin{array}{l}\text { Home setting } \\
\text { Clinical setting }\end{array}$ & $\begin{array}{l}30 \mathrm{~min} / \text { day, } 3 \text { days/week, } \\
4 \text { weeks }\end{array}$ \\
\hline $\begin{array}{l}\text { Assis et al. } \\
(2014) \text { [32] }\end{array}$ & Pre/post & $\begin{array}{l}\mathrm{EG}=4 \\
\mathrm{CG}=4\end{array}$ & $\begin{array}{l}50.5 \\
59.5\end{array}$ & $\begin{array}{l}>5 \text { years } \\
>4 \text { years }\end{array}$ & $\begin{array}{l}\text { Home setting } \\
\text { Clinical setting }\end{array}$ & $1 \mathrm{~h} /$ week, 4 weeks \\
\hline $\begin{array}{l}\text { Hondori et al. } \\
\text { (2015) [28] }\end{array}$ & Pre/post & 18 & 57 & $>5$ years & Clinical setting & $90 \mathrm{~s} /$ round, 3 rounds $/$ day \\
\hline $\begin{array}{l}\text { Hossain et al. } \\
\text { (2015) [27] }\end{array}$ & Pre/post & 11 & 63.72 & 2 months & Clinical setting & 1 week $/ 1$ month \\
\hline $\begin{array}{l}\text { Hoermann et al. } \\
\text { (2017) [30] }\end{array}$ & Pre/post & 12 & 61 & 2 months & Clinical setting & $30 \mathrm{~min} /$ session, 2 weeks \\
\hline $\begin{array}{l}\text { Colomer et al. } \\
\text { (2016) [33] }\end{array}$ & Pre/post & 30 & 58.3 & $>1$ year & Clinical setting & $\begin{array}{l}45 \mathrm{~min} / \text { day, } \\
5 \text { days/week }\end{array}$ \\
\hline $\begin{array}{l}\text { Hoermann et al. } \\
\text { (2014) [31] }\end{array}$ & Pre/post & 6 & 53.3 & $>5$ years & Clinical setting & $60 \mathrm{~min} / \mathrm{session}$ \\
\hline $\begin{array}{l}\text { Bank et al. } \\
\text { (2018) [29] }\end{array}$ & Pre/post & $\begin{array}{l}\text { CG: } 10 \\
\text { EG: } 10\end{array}$ & $\begin{array}{l}61.6 \\
60.5\end{array}$ & $>3$ months & Clinical setting & 35-105 min/session \\
\hline $\begin{array}{l}\text { Kaneko et al. } \\
\text { (2019) [38] }\end{array}$ & Pre/post & 11 & 54.7 & $>3$ months & Clinical setting & $80 \mathrm{~min} /$ day in 10 days \\
\hline $\begin{array}{l}\text { Park et al. } \\
\text { (2014) [34] }\end{array}$ & $\mathrm{RCT}$ & $\begin{array}{l}\text { CG: } 10 \\
\text { EG: } 10\end{array}$ & 47.38 & $>6$ months & Clinical setting & $\begin{array}{l}60 \mathrm{~min} / \text { day, } 5 \text { days/week, } \\
4 \text { weeks }\end{array}$ \\
\hline $\begin{array}{l}\text { Lee et al. (2014) } \\
\text { [35] }\end{array}$ & $\mathrm{RCT}$ & $\begin{array}{l}\text { CG: } 11 \\
\text { EG: } 10\end{array}$ & $47.9-54$ & 11.7 months & Clinical setting & $\begin{array}{l}30 \mathrm{~min} / \text { day, } 5 \text { days/week, } \\
4 \text { weeks }\end{array}$ \\
\hline Kim et al. (2012) & Pre/post & 28 & 49.35 & $>9$ months & Clinical setting & $\begin{array}{l}20 \text { min/day, } 3 \text { times/week, } \\
8 \text { weeks. }\end{array}$ \\
\hline $\begin{array}{l}\text { Jung et al. } \\
\text { (2013) [37] }\end{array}$ & Pre/post & $\begin{array}{l}\text { CG: } 5 \\
\text { EG: } 5\end{array}$ & $\begin{array}{l}58.4 \\
57.8\end{array}$ & $\begin{array}{l}7.6 \text { months } \\
7 \text { months }\end{array}$ & Clinical setting & $\begin{array}{l}20 \mathrm{~min} / \text { day, } 5 \text { times/week, } \\
4 \text { weeks }\end{array}$ \\
\hline
\end{tabular}


Table 4. The intervention outcomes of the included investigations.

\begin{tabular}{|c|c|c|c|c|}
\hline Author & $\begin{array}{l}\text { Time since } \\
\text { Stroke Onset }\end{array}$ & $\begin{array}{l}\text { Total No. of } \\
\text { Session }\end{array}$ & Measurement & Findings \\
\hline $\begin{array}{l}\text { Marcus King et al. } \\
\text { (2010) [26] }\end{array}$ & Chronic & 9 sessions & FM; WMFT; DASH & $\begin{array}{l}\text { Post-training improvement in FM } 11.8 \% \text {, respectively, } \\
\text { time improvement in WMFT } 9.58 \% \text {, improvement in } \\
\text { DASH } 19.1 \%\end{array}$ \\
\hline $\begin{array}{l}\text { Assis et al. (2014) } \\
\text { [32] }\end{array}$ & Chronic & 8 sessions & FM, ROM & $\begin{array}{l}\text { Case study 1: Improvement in FM UEMSS in both } \\
\text { groups (17-62\% in AR Group, } 4-14 \% \text { in Control Group) } \\
\text { Case study 2: Significant gain in ROM in all } \\
\text { participants (varying from } 46.7 \% \text { to } 73.9 \% \text { in AR Group, } \\
\text { varying } 61.3 \% \text { to } 90 \% \text { in Control Group) }\end{array}$ \\
\hline $\begin{array}{l}\text { Hondori et al. } \\
\text { (2015) [28] }\end{array}$ & Chronic & - & FM, BBT & $\begin{array}{l}\text { Significant improvement in FM hand/wrist FM } \\
\text { proximal subscore, BBT score in AR Game }\end{array}$ \\
\hline $\begin{array}{l}\text { Hossain et al. } \\
\text { (2015) [27] }\end{array}$ & Chronic & - & TCT & Improvement in TCT $16.74 \%$ \\
\hline $\begin{array}{l}\text { Hoermann et al. } \\
\text { (2017) [30] }\end{array}$ & 2 months & 14 sessions & FMUL, SULCS & Improvement in FMUL $35.8 \%$ and in SULCS $28.8 \%$ \\
\hline $\begin{array}{l}\text { Colomer et al. } \\
\text { (2016) [33] }\end{array}$ & Chronic & 30 sessions & WMFT, BBT, NHPT, FM & $\begin{array}{l}\text { Improvement in FM } 1.79 \% \text { (AR) vs. } 1.39 \% \text { (control) } \\
\text { Improvement in WMFT } 7.8 \% \text { (AR) vs. } 2.9 \% \text { (control) }(p \\
<0.01) \\
\text { Improvement in BBT } 11.2 \% \text { (AR) vs. } 2.0 \% \text { (control) }(p< \\
0.01) \\
\text { Improvement in NHPT } 15.7 \% \text { (AR) vs. } 3.14 \% \text { (control) } \\
(p<0.01)\end{array}$ \\
\hline $\begin{array}{l}\text { Hoermann et al. } \\
\text { (2014) [31] }\end{array}$ & Chronic & 24 sessions & FM & Improvements in FM $43.75 \%$ \\
\hline $\begin{array}{l}\text { Bank et al. (2018) } \\
\text { [29] }\end{array}$ & $>3$ months & - & Movement speed & Improvement in movement speed $15.5 \%$ \\
\hline $\begin{array}{l}\text { Kaneko et al. } \\
\text { (2019) [38] }\end{array}$ & $>3$ months & - & $\begin{array}{l}\text { FM, MAS, MAL, ARAT, } \\
\text { BBT }\end{array}$ & $\begin{array}{l}\text { Significant improvement in the FM } 8.61 \%(p=0.003), \\
\text { the MAS ( } p=0.001 \text { with wrist flexor muscles, } p=0.008 \\
\text { with 2nd to 5th finger flexor muscles), the MAL ( } p= \\
0.007) \text {, the total ARAT score }(p=0.018) \text {. } \\
\text { Improvement in BBT score } 54 \%(p=0.066)\end{array}$ \\
\hline $\begin{array}{l}\text { Park et al. (2014) } \\
{[34]}\end{array}$ & Chronic & 20 sessions & BBS, $10 \mathrm{MWT}$ & $\begin{array}{l}\text { Significant improvement in the BBS } 11.46 \% \text { (AR) vs. } \\
4.35 \% \text { (control) }(p<0.05) \\
\text { Significant improvement in the } 10 \text { MWT } 39.49 \% \text { (AR) vs. } \\
14.1 \% \text { (control) ( } p<0.05) \\
\text { Improvement in BBS } 8.95 \% \text { (AR) vs. } 4.17 \% \text { (control) }\end{array}$ \\
\hline $\begin{array}{l}\text { Lee et al. (2014) } \\
\text { [35] }\end{array}$ & Chronic & 12 sessions & $\begin{array}{l}\text { TUG, BBS, Gait velocity } \\
(\mathrm{cm} / \mathrm{s})\end{array}$ & $\begin{array}{l}\text { Time improvement in TUG } 18.95 \% \text { (AR) vs. } 8.97 \% \\
\text { (control) } \\
\text { Improvement in Gait velocity } 37.38 \% \text { (AR) vs. } 8.47 \% \\
\text { (control) }\end{array}$ \\
\hline $\begin{array}{l}\text { Kim et al. (2012) } \\
\text { [36] }\end{array}$ & Chronic & 24 sessions & BBS, TUG & $\begin{array}{l}\text { Improvement in BBS } 21.65 \% \text { (AR) vs. } 21.22 \% \text { (control) } \\
\text { Time improvement in TUG } 22.43 \% \text { (AR) vs. } 13.27 \% \\
\text { (control) }\end{array}$ \\
\hline $\begin{array}{l}\text { Jung et al. (2013) } \\
\text { [37] }\end{array}$ & Chronic & 12 sessions & Muscle strength & $\begin{array}{l}\text { Improvement in Medical GCM dorsiflexion } 56.48 \% \text { (AR) } \\
\text { vs. } 3.81 \% \text { (control) } \\
\text { Improvement in Medical GCM plantarflexion } 78.45 \% \\
\text { (AR) vs. } 9.33 \% \text { (control) } \\
\text { Improvement in Lateral GCM plantarflexion } 35.2 \% \text { (AR) } \\
\text { vs. } 20.13 \% \text { (control) } \\
\text { Improvement in Lateral GCM dorsiflexion } 31.08 \% \text { (AR) } \\
\text { vs. } 62.46 \% \text { (control) } \\
\text { Improvement in ankle range of motion } 17.77 \% \text { (AR) vs. } \\
12.17 \% \text { (control) }\end{array}$ \\
\hline
\end{tabular}

Abbreviations: FM, Fugl-Meyer Arm Scale; WMFT, Wolf Motor Function Test; DASH, Disabilities of the Arm, Shoulder hand questionnaire; F-M UEMSS, Fugl-Meyer upper extremity motor status score; ROM, range of motion; MAS, Modified Ashworth Scale; ARAT, Action research arm test; MAL, Motor activity log; BBT, Box \& Block Test; TCT, task completion time; NHPT, Nine Hole Peg Test; FMUL, Fugl-Meyer Upper Limb; SULCS, stroke upper limb capacity scale; BBS, Berg Balance Scale; 10 MWT, 10-Meter Walk Test; TUG, timed up and go; GCM, gastrocnemius muscle.

\subsection{Evaluation}

Two investigations recruited 20 patients [29,34], 3 investigations have a sample size over 20 [32,34,35], and 8 investigations have less than 20 participants [26-28,30-32,37,38]. The age range of the recruited patients was from 18 to 63 years old (mean $=53.7$ years; standard deviation $(\mathrm{SD})=10.44)$. The time post stroke onset ranged from 2 months to 
5 years. The intervention was delivered within the period from 1 to 4 weeks $(n=9)$. The duration of one session was from $30 \mathrm{~min}$ to $1 \mathrm{~h}(\mathrm{n}=10)$. The QualSyst scores of the included articles were summarized in Table 5. They represented high quality with a mean of $80.99 \%$, a standard deviation of 0.14 , a maximum of $95.9 \%$, and a minimum of $56.7 \%$.

Table 5. The assessed outcomes in the QualSyst of the included investigations.

\begin{tabular}{lll}
\hline Authors & Averaged Summary Score & $\begin{array}{l}\text { Standard Deviation between } \\
\text { Reviewers 1 and 2 }\end{array}$ \\
\hline Marcus King et al. (2010) [26] & $68.8 \%$ & 0.088 \\
Assis et al. (2014) [32] & $59.9 \%$ & 0.023 \\
Hondori et al. (2015) [28] & $86 \%$ & 0.004 \\
Hossain et al. (2015) [27] & $83.2 \%$ & 0.035 \\
Hoermann et al. (2017) [30] & $66.1 \%$ & 0.009 \\
Colomer et al. (2016) [33] & $91 \%$ & 0.025 \\
Hoermann et al. (2014) [31] & $76.4 \%$ & 0.02 \\
Bank et al. (2018) [29] & $95.9 \%$ & 0.005 \\
Kaneko et al. (2019) [38] & $93.2 \%$ & 0.033 \\
Park et al. (2014) [34] & $94.7 \%$ & 0.025 \\
Lee et al. (2014) [35] & $94.4 \%$ & 0.029 \\
Kim et al. (2012) [36] & $86.6 \%$ & 0.028 \\
Jung et al. (2013) [37] & $56.7 \%$ & 0.023 \\
\hline
\end{tabular}

About the upper limb rehabilitation, most studies used 4 weeks for the duration of the intervention. More of the studies ( 5 studies) recruited participants more than 1 year after stroke [26,28,31-33], with the remaining trials recruiting participants within 2 or 3 months after stroke (4 studies) [26,28,29,37]. Fugl-Meyer was used by 7 investigations, Wolf Motor Function test by 2 investigations, and Box and Block Test by 3 investigations. Following the International Classification of Functioning, Disability, and Health, the Fugl-Meyer [39] is at the body structure and function level as the motor impairment group. The Wolf Motor Function test [40] and the Box and Block test [41] are at the body activities and participation level as the motor function group.

Results of meta-analysis indicated that the AR group had a significant efficacy on overall function of upper limb rehabilitation $(\mathrm{n}=9$, SMD $=0.657,95 \% \mathrm{CI}=0.287 \sim 1.026$, $\left.\mathrm{I}^{2}=57.033 \%, p<0.001\right)$, but its heterogeneity is remarkably high $\left(\mathrm{I}^{2}=57.033 \%>50 \%\right)$ (Figure 3). The forest plot showed one outlier, which reported a large effect size (SMD = 2.689). Without the outlier, the summary effect size decreased $(n=8, \mathrm{SMD}=0.484,95 \% \mathrm{CI}=0.249 \sim 0.719$, $\mathrm{I}^{2}=0.000$ ) (Figure 4). Substantial improvement of the AR compared to the baseline was $32.5 \%(95 \% \mathrm{CI}=10.8 \sim 54.2 \%, p<0.005$; Figure 5$)$ on the motor impairment and $38 \%$ $(95 \% \mathrm{CI}=7.5 \sim 68.4 \%, p<0.02$; Figure 6$)$ on the motor function, respectively. Furthermore, Figure 7 demonstrated that AR is moderately more effective in improving the function of the upper limb than conventional therapies (59.3\% of improvement, $p<0.05)$. From these results, we also suggest that this approach can be used with the conventional rehabilitation methods as a new intervention to enhance upper limb function. Three papers with 49 participants identified significant effectiveness in favor of the AR group [26,30,35]. No adverse event was reported in these studies. Although the AR showed improvements in the recovery of the upper limb, the studies were only evaluated in a small sample size. This illustrates the approach is still in the beginnings of progression in upper limb rehabilitation. 
Improvement of Upper Limb Rehabilitation: Post versus Pre AR Group

Study name

$\begin{array}{lrrrr} & \begin{array}{c}\text { Std diff } \\ \text { in means }\end{array} & \begin{array}{c}\text { Lower } \\ \text { limit }\end{array} & \begin{array}{c}\text { Upper } \\ \text { limit }\end{array} & \text { p-Value } \\ \text { King et al., 2010 } & 0.291 & -0.712 & 1.294 & 0.570 \\ \text { Assis et al., 2014 } & 0.744 & -0.363 & 1.852 & 0.188 \\ \text { Hondori et al., 2015 } & 2.689 & 1.638 & 3.740 & 0.000 \\ \text { Hoermann et al., 2017 } & 0.580 & -0.034 & 1.195 & 0.064 \\ \text { Hoermann et al., 2014 } & 0.332 & -0.489 & 1.154 & 0.428 \\ \text { Hossain et al., 2015 } & 0.332 & -0.275 & 0.939 & 0.284 \\ \text { Colomer et al., 2016 } & 0.524 & 0.078 & 0.970 & 0.021 \\ \text { Bank et al., 2018 } & 0.253 & -0.376 & 0.883 & 0.430 \\ \text { Kaneko et al., 2019 } & 0.885 & 0.150 & 1.620 & 0.018 \\ & 0.657 & 0.287 & 1.026 & 0.000\end{array}$

Std diff in means and $95 \%$ CI

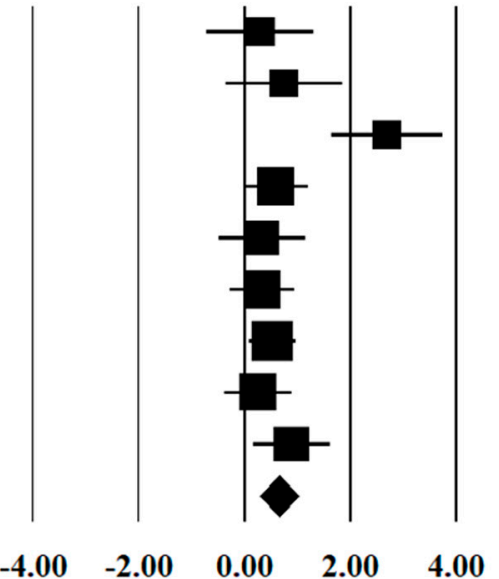

Heterogeneity: $X^{2}=18.619, \mathrm{df}=8(p=0.017) I^{2}=57.033 \%$

Figure 3. The meta-analysis results of the included investigations in the upper limb rehabilitation.

Improvement of Upper Limb Rehabilitation: Post versus Pre AR Group

Study name

Assis et al., 2014

Hoermann et al., 2017

Hoermann et al., 2014

Hossain et al., 2015

Colomer et al., 2016

Bank et al., 2018

Kaneko et al., 2019
Statistics for each study

Std diff Lower Upper

in means limit limit p-Value

$\begin{array}{llll}0.291 & -0.712 & 1.294 & 0.570 \\ 0.744 & -0.363 & 1.852 & 0.188 \\ 0.580 & -0.034 & 1.195 & 0.064 \\ 0.332 & -0.489 & 1.154 & 0.428 \\ 0.332 & -0.275 & 0.939 & 0.284 \\ 0.524 & 0.078 & 0.970 & 0.021 \\ 0.253 & -0.376 & 0.883 & 0.430 \\ 0.885 & 0.150 & 1.620 & 0.018 \\ 0.484 & 0.249 & 0.719 & 0.000\end{array}$

Std diff in means and $95 \%$ CI

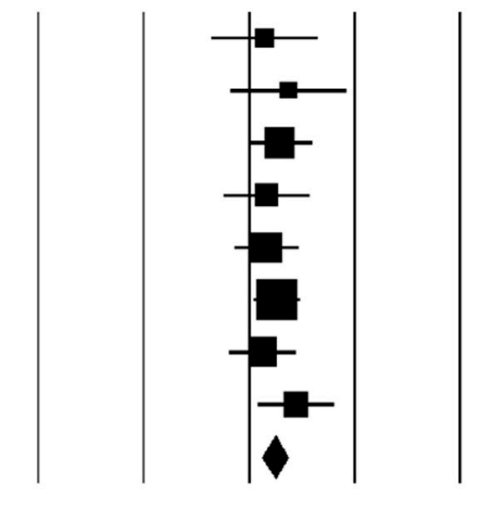

$\begin{array}{rrrrr}-4.00 & -2.00 & 0.00 & 2.00 & 4.00\end{array}$

Heterogeneity: $X^{2}=2.510, d f=7(p=0.926) I^{2}=0.000 \%$

Figure 4. The meta-analysis results of the included investigations in the upper limb rehabilitation except for the outlier. 
Improvement of Motor Impairment

Study name

$\begin{array}{lrrrrr} & \begin{array}{c}\text { Std diff } \\ \text { in means }\end{array} & \begin{array}{c}\text { Lower } \\ \text { limit }\end{array} & \begin{array}{c}\text { Upper } \\ \text { limit }\end{array} & \text { p-Value } \\ \text { King et al., 2010 } & 0.336 & -0.671 & 1.343 & 0.513 \\ \text { Assis et al., 2014 } & 0.744 & -0.363 & 1.852 & 0.188 \\ \text { Hoermann et al., 2017 } & 0.580 & -0.034 & 1.195 & 0.064 \\ \text { Hoermann et al., 2014 } & 0.332 & -0.489 & 1.154 & 0.428 \\ \text { Hossain et al., 2015 } & 0.332 & -0.275 & 0.939 & 0.284 \\ \text { Colomer et al., 2016 } & 0.114 & -0.245 & 0.474 & 0.533 \\ \text { Bank et al., 2018 } & 0.253 & -0.376 & 0.883 & 0.430 \\ \text { Kaneko et al., 2019 } & 0.643 & -0.006 & 1.292 & 0.052 \\ & 0.325 & 0.108 & 0.542 & 0.003\end{array}$

\section{Std diff in means and $95 \%$ CI}

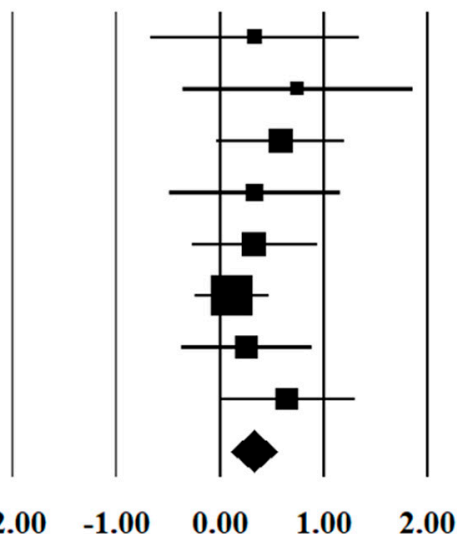

Heterogeneity: $\mathrm{X}^{2}=3.506, \mathrm{df}=7(\mathrm{p}=0.835) \mathrm{I}^{2}=0.000$

Figure 5. The meta-analysis results of the included investigations in the motor impairment improvement of the upper limb rehabilitation.

\section{Improvement of Motor Function}

\section{Study name}

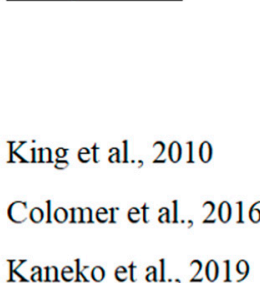

Kaneko et al., 2019

\section{Statistics for each study}

$\begin{array}{ccc}\text { Std diff } & \text { Lower } & \text { Upper } \\ \text { in means } & \text { limit } & \text { limit }\end{array}$

$\begin{array}{llll}0.268 & -0.733 & 1.270 & 0.599 \\ 0.368 & -0.004 & 0.741 & 0.053 \\ 0.454 & -0.167 & 1.075 & 0.152 \\ 0.380 & 0.075 & 0.684 & 0.014\end{array}$
p-Value

\section{Std diff in means \\ and $95 \% \mathrm{CI}$}

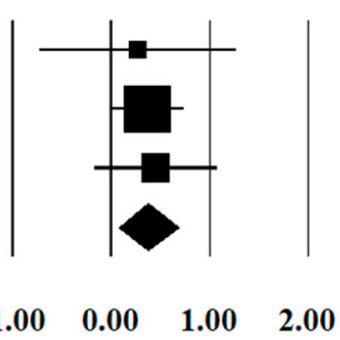

Heterogeneity: $X^{2}=0.106, \mathrm{df}=2(\mathrm{p}=0.948) \mathrm{I}^{2}=0.000$

Figure 6. The meta-analysis results of the included investigations in the motor function improvement of the upper limb rehabilitation.

On the function of lower limb rehabilitation, four studies with 79 participants measured the effects of AR intervention. All studies consisted of people who were chronic stroke survivors. The meta-analysis showed that the overall effect of the AR was SMD $=0.520$ $(95 \%$ CI $=0.039 \sim 1.001, p<0.05$, Figure 8$)$. Nevertheless, there was no significant effect on the Berg balance scale (BBS) $(\mathrm{SMD}=0.405,95 \% \mathrm{CI}=-0.112 \sim 0.921, p=0.125$; Figure 9 ) nor time up and go (TUG) $(\mathrm{SMD}=0.3,95 \% \mathrm{CI}=-0.333 \sim 0.932 ; p=0.353$; Figure 10$)$. Although there was a moderately significant improvement of the AR intervention versus the conventional therapy, the AR intervention was only used to increase the dose of usual care. It means that these collected studies used the comparison of conventional therapy alone versus an AR intervention plus conventional therapy. Consequently, the AR group had more treatment duration than the control group. This induced a positive tendency of the AR group due to the greater intensity and frequency of rehabilitation. 
Study name

Assis et al., 2014
Statistics for each study

$\begin{array}{rrrr}\begin{array}{c}\text { Std diff } \\ \text { in means }\end{array} & \begin{array}{c}\text { Lower } \\ \text { limit }\end{array} & \begin{array}{c}\text { Upper } \\ \text { limit }\end{array} & \text { p-Value } \\ 0.428 & -0.974 & 1.830 & 0.549 \\ 0.620 & 0.059 & 1.180 & 0.030 \\ 0.593 & 0.073 & 1.114 & 0.025\end{array}$

Std diff in means and $95 \% \mathrm{CI}$

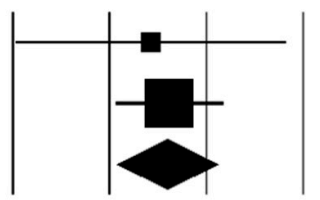

$\begin{array}{rrrrr}2.00 & -1.00 & 0.00 & 1.00 & 2.00\end{array}$

Heterogeneity: $X^{2}=0.062, \mathrm{df}=1(\mathrm{p}=0.803) I^{2}=0.000$

Figure 7. The meta-analysis results of the included investigations in comparing between the AR group and the conventional therapy group of the upper limb rehabilitation.

Improvement of Balance and Gait Function

Study name

$\begin{array}{lrrrr} & \begin{array}{c}\text { Std diff } \\ \text { in means }\end{array} & \begin{array}{c}\text { Lower } \\ \text { limit }\end{array} & \begin{array}{c}\text { Upper } \\ \text { limit }\end{array} & \text { p-Value } \\ \text { Park et al., 2014 } & 0.570 & -0.324 & 1.464 & 0.211 \\ \text { Lee et al., 2014 } & 0.422 & -0.446 & 1.290 & 0.341 \\ \text { Kim et al., 2012 } & 0.524 & -0.418 & 1.465 & 0.276 \\ \text { Jung et al., 2013 } & 0.625 & -0.654 & 1.904 & 0.338 \\ & 0.520 & 0.039 & 1.001 & 0.034\end{array}$

Std diff in means and $95 \% \mathrm{CI}$

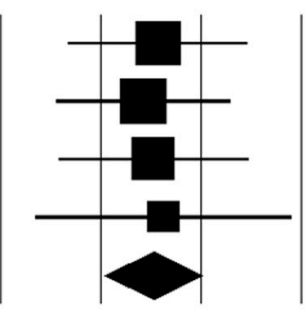

$\begin{array}{lllll}-2.00 & -1.00 & 0.00 & 1.00 & 2.00\end{array}$

Heterogeneity: $\mathrm{X}^{2}=0.087, \mathrm{df}=3(\mathrm{p}=0.993) \mathrm{I}^{2}=0.000$

Figure 8. The meta-analysis results of the included investigations in the lower limb rehabilitation.

\section{Improvement of Berg Balance Scale}

Study name

$\begin{array}{lrrrrr} & \begin{array}{c}\text { Std diff } \\ \text { in means }\end{array} & \begin{array}{c}\text { Lower } \\ \text { limit }\end{array} & \begin{array}{c}\text { Upper } \\ \text { limit }\end{array} & \text { p-Valu } \\ \text { Park et al., 2018 } & 0.558 & -0.335 & 1.452 & 0.22 \\ \text { Lee et al., 2018 } & 0.398 & -0.467 & 1.263 & 0.367 \\ \text { Kim et al., 2012 } & 0.246 & -0.681 & 1.173 & 0.603 \\ & 0.405 & -0.112 & 0.921 & 0.12\end{array}$

Std diff in means and $95 \% \mathrm{CI}$

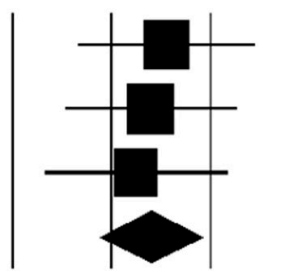

$$
\begin{array}{lllll}
-2.00 & -1.00 & 0.00 & 1.00 & 2.00
\end{array}
$$

Heterogeneity: $\mathrm{X}^{2}=0.226, \mathrm{df}=2(\mathrm{p}=0.893) \mathrm{I}^{2}=0.000$

Figure 9. The meta-analysis results of the included investigations in the Berg Balance Scale improvement of the lower limb rehabilitation. 
Improvement of Time Up and Go Test

Study name

Lee et al., 2018

Kim et al., 2012

\section{Statistics for each study}

$\begin{array}{rcrr}\begin{array}{c}\text { Std diff } \\ \text { in means }\end{array} & \begin{array}{c}\text { Lower } \\ \text { limit }\end{array} & \begin{array}{c}\text { Upper } \\ \text { limit }\end{array} & \text { p-Value } \\ 0.147 & -0.710 & 1.005 & 0.736 \\ 0.481 & -0.456 & 1.419 & 0.314 \\ 0.300 & -0.333 & 0.932 & 0.353\end{array}$

\section{Std diff in means}

and $95 \% \mathrm{CI}$

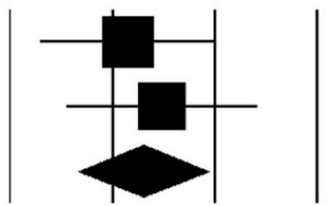

$\begin{array}{rrrrr}-2.00 & -1.00 & 0.00 & 1.00 & 2.00\end{array}$

Heterogeneity: $X^{2}=0.266, \mathrm{df}=1(\mathrm{p}=0.606) \mathrm{I}^{2}=0.000$

Figure 10. The meta-analysis results of the included investigations in the Time Up and Go Test improvement of the lower limb rehabilitation.

Finally, Figure 11a,b showed the symmetrical shape on the funnel plot. Therefore, the publication bias did not exist in the evaluation results based on statistical approaches ( $p$-value of Egger's test for upper limb is 0.823 and $p$-value of Egger's test for lower limb is $p=0.331)$.

\subsection{Comparison with the Literature}

Our results demonstrate the AR approach is still in the beginnings of progression in upper limb rehabilitation. This is consistent with the main findings of previous studies [18-21]. In addition, we also observed that combining AR with conventional rehabilitation for stroke patients is more beneficial than only conventional therapy based on statistically significant results through meta-analysis. Therefore, this approach can be used width the conventional rehabilitation methods as a new intervention for recovering upper and lower limb function.
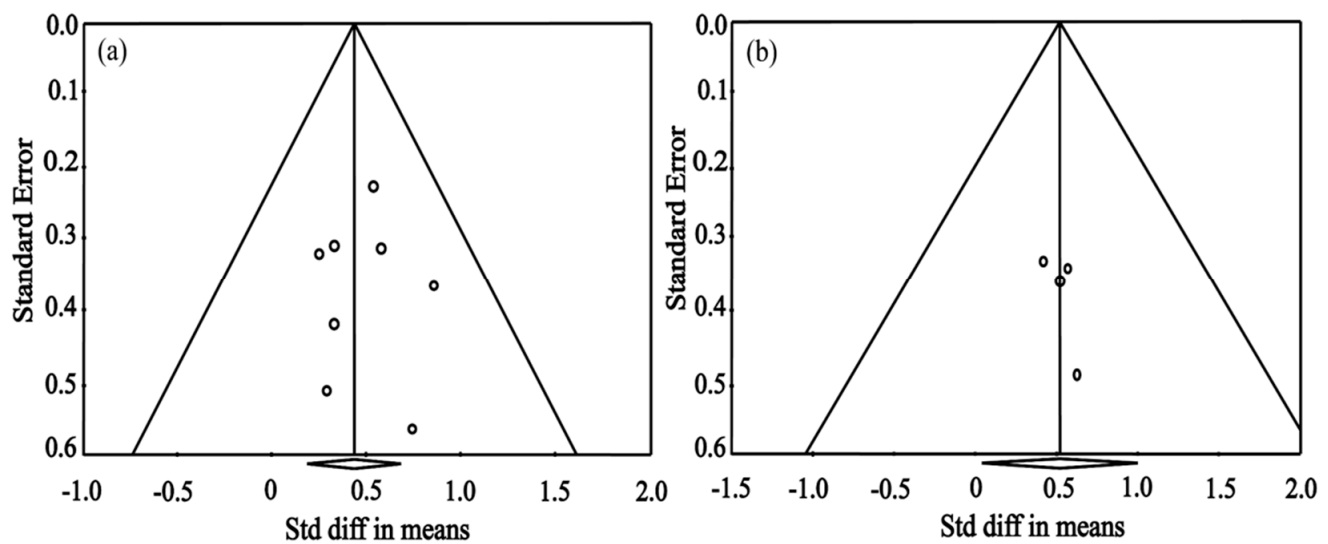

Figure 11. The funnel plot for the publication bias of the included investigations on (a) the upper limb rehabilitation, (b) the lower limb rehabilitation.

\subsection{Potential Implications for Clinicians}

Although AR is still in the developing stage in stroke rehabilitation, AR systems showed they are promising for the improvement of lower limb function and upper limb function in this meta-analysis. In addition, physiotherapists' and patients' experiences were surveyed in some studies. Users preferred a system that provided automatic instructions and feedback. They discovered that the AR technique was useful, motivating, attractive, and valuable for their function recovery $[16,29,30,32]$. This similar positive feedback was 
also found by therapists [30]. To obtain this positive feedback, they can be derived from multiple important factors of AR systems. The first reason is that AR systems employ important factors for promoting neuroplasticity such as repetition, intensity, and task-oriented training in the paretic extremity, which induces improvement in stroke rehabilitation. Moreover, the AR rehabilitation systems provide a sense of realism to the patients during the exercising process $[29,37,42,43]$ based on the range of sensory feedback provided by the AR systems. Various exercises in AR systems are another reason for the positive responses. Here, depending on the patients' needs and actual motor skills, the therapist or patients could select the appropriate therapy modes. Additionally, the training intensity could be automatically modified to suit the patients' motor condition by creating a personal training program in AR systems.

However, some drawbacks of AR were described, such as the wearing of HMD inducing side effects during and after the intervention such as fatigue, and nausea. This simulator sickness is a critical issue in medical applications. Other challenges consisted of: (1) the patients might find it difficult to perceive depth of view, so they felt it was difficult to reach the desired position in the 3D environment; (2) the AR applications have relied on tracking methods in the prepared environment, meaning that it is almost impossible to apply in unprepared environments. Future research needs to overcome these shortcomings.

\section{Conclusions}

This paper aimed to systematically review the effect of the AR in the upper and lower limb rehabilitation of stroke patients. The present analysis suggests that AR applications could offer options for increasing treatment intensity and promoting motor recovery after a stroke. This approach can be used with the conventional rehabilitation methods as a new intervention for recovering upper and lower limb function. To verify our findings, further long-term clinical trials with large sample sizes are required. In addition, the efficacy of AR treatment on the recovery of upper and lower limb function in different genders and age groups should also be investigated further.

To overcome the drawbacks of the current AR system and make AR widespread in the rehabilitation field, some perspectives for future AR rehabilitation systems should be integrated alongside many technologies and modern devices such as artificial intelligence, the internet of things, and a larger field-of-view HMD, because these high technologies can intelligently adapt exercises based on users' progress and feedbacks. In addition, they can provide various interfaces, diverse training programs, higher accuracy tracking, and higher quality of presence and embodiment for users. To increase the users' motivation during treatment, designing attractive content for the AR system is required, but there is also a need to design a user-friendly, portable, and low-cost system. Finally, managing and monitoring the heath and progress of users should be applied in AR rehabilitation systems. This feature is necessary to establish telerehabilitation that can monitor the change in personal activities and behavior in real time during or after treatment, then, it will communicate with healthcare professionals.

Author Contributions: Study objective: H.L.P., K.-i.K., C.H.H.; literature search: H.L.P., T.H.L.; data extraction: H.L.P., T.H.L.; methodological quality assessment: H.L.P., T.H.L., J.M.L., K.-i.K.; critical review and approval of manuscript: H.L.P., T.H.L., J.M.L., K.-i.K., C.H.H. All authors have read and agreed to the published version of the manuscript.

Funding: This work was supported by the 2020 Research Fund of University of Ulsan, Ulsan, Republic of Korea.

Institutional Review Board Statement: Not applicable.

Informed Consent Statement: Not applicable.

Data Availability Statement: Not applicable.

Conflicts of Interest: The author(s) declared no potential conflicts of interest with respect to the authorship and/or publication of this article. 


\section{References}

1. Association, A.H. Heart Disease and Stroke Statistics-2006 Update. Circulation 2006, 113, e85-e151. [CrossRef]

2. World Health Organization. World Report on Disability; World Health Organization: Geneva, Switzerland, 2011.

3. Lunde, L.-K.; Koch, M.; Knardahl, S.; Wærsted, M.; Mathiassen, S.E.; Forsman, M.; Holtermann, A.; Veiersted, K.B. Musculoskeletal health and work ability in physically demanding occupations study protocol for a prospective field study on construction and health care workers. BMC Public Health 2014, 14, 1075. [CrossRef] [PubMed]

4. Chatterji, S.; Byles, J.; Cutler, D.; Seeman, T.; Verdes, E. Health, functioning, and disability in older adults-present status and future implications. Lancet 2015, 385, 563-575. [CrossRef]

5. Hanssen, J.-I.; Lindqvist, R. Rehabilitation; Concepts, Practices and Research. Scand. J. Disabil. Res. 2003, 5, 3-6. [CrossRef]

6. Borich, M.R.; Wolf, S.L.; Tan, A.Q.; Palmer, J.A. Targeted Neuromodulation of Abnormal Interhemispheric Connectivity to Promote Neural Plasticity and Recovery of Arm Function after Stroke: A Randomized Crossover Clinical Trial Study Protocol. Neural Plast. 2018, 2018, 9875326. [CrossRef]

7. Alia, C.; Spalletti, C.; Lai, S.; Panarese, A.; Lamola, G.; Bertolucci, F.; Vallone, F.; Di Garbo, A.; Chisari, C.; Micera, S.; et al. Neuroplastic Changes Following Brain Ischemia and their Contribution to Stroke Recovery: Novel Approaches in Neurorehabilitation. Front. Cell. Neurosci. 2017, 11, 1-22. [CrossRef]

8. Mehta, U.M.; Keshavan, M.S. Cognitive Rehabilitation and Modulating Neuroplasticity with Brain Stimulation: Promises and Challenges. J. Psychosoc. Rehabil. Ment. Health 2015, 2, 5-7. [CrossRef]

9. Huang, L.L.; Lee, C.F.; Hsieh, C.L.; Chen, M.H. Upper extremity rehabilitation equipment for stroke patients in Taiwan: Usage problems and improvement needs. Occup. Ther. Int. 2013, 20, 205-214. [CrossRef]

10. Druzbicki, M.; Przysada, G.; Guzik, A.; Brzozowska-Magon, A.; Kolodziej, K.; Wolan-Nieroda, A.; Majewska, J.; Kwolek, A. The Efficacy of Gait Training Using a Body Weight Support Treadmill and Visual Biofeedback in Patients with Subacute Stroke: A Randomized Controlled Trial. BioMed Res. Int. 2018, 2018, 1-11. [CrossRef]

11. Bickerton, W.L.; Humphreys, G.W.; Riddoch, J.M. The use of memorised verbal scripts in the rehabilitation of action disorganisation syndrome. Neuropsychol. Rehabil. 2006, 16, 155-177. [CrossRef]

12. Forde, E.M.E.; Humphreys, G.W. Dissociations in Routine Behaviour across Patients and Everyday Tasks. Neurocase 2002, 8, 151-167. [CrossRef] [PubMed]

13. Burdea, G. Virtual Rehabilitation-Benefits and Challenges. Methods Inf. Med. 2003, 42, 519-523. [CrossRef] [PubMed]

14. Azuma, R.; Baillot, Y.; Behringer, R.; Feiner, S.; Julier, S.; MacIntyre, B. Recent Advances in Augmented Reality. IEEE Comput. Graph. Appl. 2001, 21,34-47. [CrossRef]

15. Sigrist, R.; Rauter, G.; Riener, R.; Wolf, P. Augmented visual, auditory, haptic, and multimodal feedback in motor learning: A review. Psychon. Bull. Rev. 2013, 20, 21-53. [CrossRef]

16. Da Gama, A.E.; Chaves, T.M.; Figueiredo, L.S.; Baltar, A.; Meng, M.; Navab, N.; Teichrieb, V.; Fallavollita, P. MirrARbilitation: A clinically-related gesture recognition interactive tool for an AR rehabilitation system. Comput. Methods Programs Biomed. 2016, 135, 105-114. [CrossRef]

17. Tang, A.; Biocca, F. Comparing Differences in Presence during Social Interaction in Augmented Reality versus Virtual Reality Environments An Exploratory Study. In Proceedings of the PRESENCE 2004, Seventh Annual International Workshop on Presence, Valencia, Spain, 13-15 October 2004; pp. 204-207.

18. Ong, S.K.; Shen, Y.; Zhang, J.; Nee, A.Y.C. Augmented Reality in Assistive Technology and Rehabilitation Engineering; Springer: New York, NY, USA, 2011; pp. 603-630. [CrossRef]

19. Al-Issa, H.; Regenbrecht, H.; Hale, L. Augmented reality applications in rehabilitation to improve physical outcomes. Phys. Ther. Rev. 2012, 17, 16-28. [CrossRef]

20. Rosanna Maria Viglialoro, S.C.; Turini, G.; Carbone, M.; Ferrari, V.; Gesi, M. Review of the Augmented Reality Systems for Shoulder Rehabilitation. Information 2019, 10, 154. [CrossRef]

21. Gorman, C.; Gustafsson, L.A.-O. The use of augmented reality for rehabilitation after stroke: A narrative review. Disabil. Rehabil. Assist. Technol. 2020, 1-9. [CrossRef]

22. Moher, D.; Liberati, A.; Tetzlaff, J.; Altman, D.G.; Group, P. Preferred reporting items for systematic reviews and meta-analyses: The PRISMA statement. BMJ 2009, 339, b2535. [CrossRef]

23. WHO. The International Classification of Functioning, Disability and Health; WHO: Geneva, Switzerland, 2002.

24. Aminov, A.A.-O.; Rogers, J.M.; Middleton, S.; Caeyenberghs, K.; Wilson, P.H. What do randomized controlled trials say about virtual rehabilitation in stroke? A systematic literature review and meta-analysis of upper-limb and cognitive outcomes. $J$. Neuroeng. Rehabil. 2018, 15, 29. [CrossRef]

25. Kmet, L.M.; Lee, R.C.; Cook, L.S. Standard Quality Assessmemt Criteria for Evaluating Primary Research Papers from a Variety of Fields; Institute of Health Economics: Dhaka, AB, Canada, 2004.

26. King, M.; Hale, L.; Pekkari, A.; Persson, M.; Gregorsson, M.; Nilsson, M. An affordable, computerised, table-based exercise system for stroke survivors. Disabil. Rehabil. Assist. Technol. 2010, 5, 288-293. [CrossRef] [PubMed]

27. Hossain, M.S.; Hardy, S.; Alamri, A.; Alelaiwi, A.; Hardy, V.; Wilhelm, C. AR-based serious game framework for post-stroke rehabilitation. Multimed. Syst. 2015, 22, 659-674. [CrossRef]

28. Mousavi Hondori, H.; Khademi, M.; Dodakian, L.; McKenzie, A.; Lopes, C.V.; Cramer, S.C. Choice of Human-Computer Interaction Mode in Stroke Rehabilitation. Neurorehabilit. Neural Repair 2015, 30, 258-265. [CrossRef] 
29. Bank, P.J.M.; Cidota, M.A.; Ouwehand, P.E.W.; Lukosch, S.G. Patient-Tailored Augmented Reality Games for Assessing Upper Extremity Motor Impairments in Parkinson's Disease and Stroke. J. Med. Syst. 2018, 42, 246. [CrossRef] [PubMed]

30. Hoermann, S.; Ferreira Dos Santos, L.; Morkisch, N.; Jettkowski, K.; Sillis, M.; Devan, H.; Kanagasabai, P.S.; Schmidt, H.; Kruger, J.; Dohle, C.; et al. Computerised mirror therapy with Augmented Reflection Technology for early stroke rehabilitation: Clinical feasibility and integration as an adjunct therapy. Disabil. Rehabil. 2017, 39, 1503-1514. [CrossRef]

31. Hoermann, S.; Hale, L.; Winser, S.J.; Regenbrecht, H. Patient engagement and clinical feasibility of Augmented Reflection Technology for stroke rehabilitation. Int. J. Disabil. Hum. Dev. 2014, 13, 355-360. [CrossRef]

32. Assis, G.A.; Correa, A.G.; Martins, M.B.; Pedrozo, W.G.; Lopes Rde, D. An augmented reality system for upper-limb post-stroke motor rehabilitation: A feasibility study. Disabil. Rehabil. Assist. Technol. 2014, 11, 521-528. [CrossRef]

33. Colomer, C.; Llorens, R.; Noe, E.; Alcaniz, M. Effect of a mixed reality-based intervention on arm, hand, and finger function on chronic stroke. J. NeuroEng. Rehabil. 2016, 13, 521-528. [CrossRef]

34. Park, Y.H.; Lee, C.H.; Kim, H.J. A pilot study of augmented reality-based postural control training in stroke rehabilitation. Phys. Ther. Rehabil. Sci. 2014, 3, 13-19. [CrossRef]

35. Lee, C.-H.; Kim, Y.; Lee, B.-H. Augmented reality-based postural control training improves gait function in patients with stroke: Randomized controlled trial. Hong Kong Physiother. J. 2014, 32, 51-57. [CrossRef]

36. Kim, I.C.; Lee, B.H. Effects of Augmented Reality with functional electric Stimulation on Muscle Strength, Balance and Gait of Stroke patients. J. Phys. Ther. Sci. 2012, 24, 755-762. [CrossRef]

37. Jung, G.U.; Moon, T.H.; Park, G.W.; Lee, J.Y.; Lee, B.H. Use of Augmented Reality-Based Training with EMG-Triggered Functional Electric Stimulation in Stroke Rehabilitation. J. Phys. Ther. Sci. 2013, 25, 147-151. [CrossRef]

38. Kaneko, F.; Shindo, K.; Yoneta, M.; Okawada, M.; Akaboshi, K.; Liu, M. A Case Series Clinical Trial of a Novel Approach Using Augmented Reality That Inspires Self-body Cognition in Patients With Stroke: Effects on Motor Function and Resting-State Brain Functional Connectivity. Front. Syst. Neurosci. 2019, 13, 76. [CrossRef] [PubMed]

39. Duncan, P.W.; Propst, M.; Nelson, S.G. Reliability of the Fugl-Meyer Assessment of Sensorimotor Recovery Following Cerebrovascular Accident. Phys. Ther. 1982, 63, 1606-1610. [CrossRef]

40. Woodbury, M.; Velozo, C.A.; Thompson, P.A.; Light, K.; Uswatte, G.; Taub, E.; Winstein, C.J.; Morris, D.; Blanton, S.; NicholsLarsen, D.S.; et al. Measurement structure of the Wolf Motor Function Test: Implications for motor control theory. Neurorehabilit. Neural Repair 2010, 24, 791-801. [CrossRef]

41. Mathiowetz, V.; Volland, G.; Kashman, N.; Weber, K. Adult norms for the Box and Block Test of Manual Dexterity. Am. J. Occup. Ther. 1985, 39, 386-391. [CrossRef]

42. Koo, K.I.; Park, D.K.; Youm, Y.S.; Cho, S.D.; Hwang, C.A.-O. Enhanced Reality Showing Long-Lasting Analgesia after Total Knee Arthroplasty: Prospective, Randomized Clinical Trial. Sci. Rep. 2018, 8, 2343. [CrossRef]

43. Phan, H.L.; Kim, J.P.; Kim, K.; Hwang, C.H.; Koo, K.-i. Wrist Rehabilitation System Using Augmented Reality for Hemiplegic Stroke Patient Rehabilitation: A Feasibility Study. Appl. Sci. 2019, 9, 2892. [CrossRef] 